\title{
The Effect of Movement on Cognitive Performance
}

\author{
Raed Mualem ${ }^{1,2,3}$, Gerry Leisman ${ }^{3,4 *}$, Yusra Zbedat', Sherif Ganem ${ }^{5}$, Ola Mualem ${ }^{3}$, \\ Monjed Amaria', Aiman Kozle ${ }^{1}$, Safa Khayat-Moughrabi ${ }^{3}$ and Alon Ornai ${ }^{2}$
}

${ }^{1}$ Ramat Zevulun High School, Ibtin, Israel, ${ }^{2}$ Oranim Academic College, Qiriat Tivon, Israel, ${ }^{3}$ The National Institute for Brain \& Rehabilitation Sciences-Israel, Nazareth, Israel, ${ }^{4}$ Faculty of Health Sciences, University of Haifa, Haifa, Israel, ${ }^{5}$ Safed Academic College, Safed, Israel

The study examines the relationship between walking, cognitive, and academic skills. Students from elementary, middle, high school, and college were required to walk for 10 min prior to completing feature detection, Simon-type memory, and mathematical problem-solving tasks. Participants were counterbalanced to remove a time bias. Ten minutes of walking had a significant positive effect on Simon-type memory and critical feature-detection tasks among all age groups. Separately, with mathematical problemsolving ability, higher performing high-school students demonstrated significant positive effects on mathematical reasoning tasks based on the Bloom Taxonomy. However, poorly achieving high-school students performed significantly better than those with higher grades in mathematics on tests of mathematical problem-solving ability based on the Bloom's Taxonomy. The study indicates that there is justification to employ relatively simple means to effect lifestyle, academic, and cognitive performance.

Keywords: sequential memory, attention, cognition, movement, walking, Bloom's taxonomy, mathematics achievement

\section{INTRODUCTION}

Brain plasticity and cognitive function are significantly improved by physical activity (1). The importance of this association is more important than ever given the significantly increased sedentary behavior and obesity worldwide in childhood and adulthood and the upsurge in aging populations of diminishing fitness and cognitive functions (2). Kramer and Erickson $(3,4)$ assessed the hypothesis that exercise and physical activity might protect and even augment brain and cognitive function throughout one's lifespan. They critically reviewed the literature on the relationship between physical activity on brain and cognition function. The authors included prospective observational or epidemiological studies; non-human animal studies; and randomized human clinical trials. They reported that the literature supports the assertion that cognitive and brain function is enhanced by physical activity.

McDonnell et al. (5) found that a single 30-min period of physical activity is related to increases in neuroplasticity with discernible positive effects in motor-skill coordination and in declarative memory. Hillman et al. (6) studied the relationship between electrophysiological variables associated with attention and treadmill walking on academic performance. Hillman and colleagues observed the cognitive function and cardiopulmonary fitness at rest of each of their participants to determine baseline aerobic and cognitive capability. An exercise period was provided that involved 20 min of walking on a treadmill at $60 \%$ of the estimated maximum heart rate followed by the assessment of cognitive function once heart rate resumed to within $10 \%$ of pre-exercise levels. The participants exhibited a significant increase in response accuracy; greater P3 event related potential amplitude, 
and significantly improved performance on academic achievement tests after aerobic exercise when compared with rest. The results of Hillman and colleague's study revealed that exercise is associated with increases in cognitive function as measured by tests of academic performance and attention. These data suggest that even single sessions of light exercise can influence essential processes related to cognitive skills.

Smith et al. (7) required adults in their late 1920s and early 1930 s to ride exercise bicycles for a period of $30 \mathrm{~min}$. Brain-state changes immediately after the session were examined and again after $15 \mathrm{~min}$. Short-interval intra-cortical inhibition before and at 0 and $15 \mathrm{~min}$ following $30 \mathrm{~min}$ of ergometer cycling at low-moderate or moderate-high intensity was examined as well as cortical stimulus-response curves (90-150\% resting motor threshold). Neuroplasticity, it was concluded, could be improved by a single 30-min session of physical activity with noticeable changes after only $15 \mathrm{~min}$ of exercising.

Neuroplasticity is associated with the both the actual number as well as the connection strength between neurons as well as in regional connectivities within the brain (8). It is on this basis that we can explain why it is that exercise and physical activity positively increase cognitive-motor function. Kamijo et al. (9) had studied the relationship between academic achievement and physical exercise, as did Hillman et al. (10). Of interest is the fact that Cotman and Berchtold (11) noted that with physical activity, brain-derived neurotrophic factor (BDNF), that supports synaptogenesis in the basal forebrain and hippocampus, functions in areas fundamental to memory, learning, and thinking and is significantly elevated in rodents. Similar findings have been found in humans (12). Interestingly, although BDNF increases in mouse hippocampus after 7 days of wheel running compared with sedentary mice (11), termination of the exercise according to Ref. (13) reverses, in rodents, the increased cell number, and cognitive gains. Chaddock-Heyman et al. (14) found advantage from regular exercise for the brain's white matter and noted that connectivities between diverse cortical gray matter brain regions were facilitated. The relationship between brain state and an individual's physical fitness was observed in 249- and 10-year-old children. Researchers observed thicker and denser white matter among those children exhibiting greater degrees of physical fitness in turn linked with significantly superior attention span, memory, and cognitive facilities.

In the present, we examined the relationship between $10 \mathrm{~min}$ of walking to determine its effects on cognitive and academic performance in various age groups.

\section{MATERIALS AND METHODS}

\section{Feature Detection and Simon-Type Memory \\ Participants}

Seventy-five elementary school children all in grade 5 consisting of 35 females and 40 males and 75 middle school children all in grade 7 (36 females and 39 males), 75 high school all in grade 9 consisting of 38 females and 37 males and 58 college students ( 35 females and 23 males) between the ages of 22 and 27 years participated in the study. All participants came from middle class backgrounds as determined by the methodology of Hollingshead and Redlich (15) IRB approval was obtained from the Research Committee of Oranim Academic College.

In the mathematic problem-solving study 75 high-school students in grade 9 consisting of 38 females and 37 males participated in the study. IRB approval was obtained from the Research Committee of Oranim Academic College.

\section{Procedure}

Participants were divided into two groups. Both groups were given a sequential memory task consisting of a Simon-type multisensory memory game (16) and a feature-detection task consisting of presentations of famous paintings twice, once with the complete painting and later with a minor feature of the painting missing. The task of each participant was to find the missing feature. Group A was given the tasks immediately after $10 \mathrm{~min}$ of outdoor walking in the school yard at a normal pace at 10 a.m. each session and Group B was given the tasks without $10 \mathrm{~min}$ of walking. A period of 10 min of walking was chosen rather than 15 min as longer periods would likely covert aerobic into anaerobic metabolism (17). After a period of a full week, Group B performed 10 min of walking prior to the task and Group A did not. Therefore, the groups were counterbalanced. This design attempted to avoid time as a confounding variable. In all cases, both the Simon-type and feature-detection tasks, all participants in both pre- and post-walking sessions were counterbalanced in that in the pre-testing situation Group A was examined prior to walking, and B after walking, with different but statistically equivalent tasks.

In the mathematical problem-solving task, participants were divided into two groups. Both groups were given a mathematical problem-solving task based on PISA, a multinational test of mathematical problem-solving ability (18). The tasks were based on Bloom's Taxonomy (remember, understanding, apply, and analyze) $(18,19)$.

We did not use the PISA test itself but rather employed "PISA-type" questions that were not part of current PISA tests but rather examples of questions typically found on PISA. We were not testing academic achievement but rather changes in mathematical problem-solving ability as measured by these question examplars-after aerobic walking.

As all groups received equivalent questions, PISA standardization became irrelevant in the context of the present study as the entire test was not used but only samples. The focus was not the PISA test results but rather changes in how the participants answered the same type of questions reflecting mathematical problem-solving ability.

Group A performed the PISA tasks immediately after $10 \mathrm{~min}$ of walking and Group B was given the tasks without $10 \mathrm{~min}$ of walking. After a period a full week, Group B had $10 \mathrm{~min}$ of walking prior to the task and Group A did not. Therefore, the groups were counterbalanced. This design attempted to avoid time confounded the results. This design attempted to avoid time as a confounding variable. All participants in both preand post-walking sessions were counterbalanced in that in the pre-testing situation Group A was examined prior to walking, 
and $\mathrm{B}$ after walking, with different but statistically equivalent tasks.

Each level of the taxonomic hierarchy contained two questions and was taken from the last edition of PISA. The questions provided the participants both before and after the walking intervention were different but statistically equivalent in difficulty. During the week between pre- and post-testing, participants had no opportunity to practice the material contained in PISA, as it was not part of their curriculum for their grades. Participants, therefore, had no practice effect. Questions were taken from the Israel Arabic edition of PISA from the ministry of education with questions exemplified in the materials provided by the OECD (20).

\section{Statistical Analysis}

Paired $t$-test comparisons were performed between pre- and post-walking tasks as each participant served as his own control. Non-parametric Spearman's rho correlations were also performed in order to examine the impact of attention on memory in the Simon-type and feature-detection tasks.

\section{RESULTS}

\section{Simon-Type Memory and Feature Detection}

The analysis created forced dichotomies between poor and highperforming students in mathematical problem solving. Weak students had a grade average of less than $60 \%$ and those defined as having a grade point average of greater than $60 \%$.

The results demonstrated significant improvement in the final PISA scores with walking of $10.6 \%(t=5.01$; df, $31 ; p<0.0001)$ and sequential memory tasks with an $11 \%$ increase in performance $(t=5.727$; df, 74; $p<0.0001)$ after $10 \mathrm{~min}$ of walking. Among middle school participants, significant improvement was recorded on feature detection with a $26 \%$ increase in performance $(t=2.39 ; \mathrm{df}, 74 ; p<0.05)$ and sequential memory tasks with a $15.4 \%$ increase in performance $(t=2.905 ; \mathrm{df}, 74 ; p<0.001)$ after $10 \mathrm{~min}$ of walking. Among high-school participants, significant improvement was recorded on feature detection with a $25 \%$ increase in performance $(t=3.48$; df, 69; $p<0.001)$ and on sequential memory tasks with an $8 \%$ increase in performance $(t=3.48$; df, 69; $p<0.001)$ after $10 \mathrm{~min}$ of walking. Among college-aged participants, significant improvement was recorded on feature detection with a $34 \%$ increase in performance $(t=5.05$; df, $57 ; p<0.001)$ and on sequential memory tasks with a $20 \%$ increase in performance ( $t=11.98$; df, 57; $p<0.001)$ after $10 \mathrm{~min}$ of walking. The tabular representation of the results may be found in Tables $\mathbf{1}$ and $\mathbf{2}$.

Table 3 reports Spearman's rho correlational data for memory and feature-detection tasks. For all age groups, no significant relationships were noted, indicating the independence of the experimental tasks and the collective effects of walking on performance.

\section{Mathematical Skill}

The present study additionally aimed to determine the effects of 10 min of walking on the effectiveness of mathematical learning performance in high-school male and female students. Participant
TABLE 1 | Simon-type memory task.

\begin{tabular}{llrrcccc}
\hline Age & & Before & After $\begin{array}{c}\text { \% Change } \\
\text { of the } \\
\text { mean }\end{array}$ & & p-Value & N \\
\hline Elementary & Mean & 7.18 & 8.08 & 11.13 & 5.7278 & 0.0001 & 75 \\
school & SD & 2.10 & 1.99 & & & & \\
Middle school & Mean & 9.15 & 10.82 & 15.49 & 2.9059 & 0.0043 & 75 \\
& SD & 3.12 & 3.59 & & & & \\
High school & Mean & 11.65 & 12.67 & 8.01 & 3.4877 & 0.0009 & 75 \\
& SD & 2.68 & 2.84 & & & & \\
College & Mean & 9.98 & 12.54 & 20.43 & 11.9825 & 0.0001 & 58 \\
& SD & 2.55 & 2.95 & & & & \\
\hline
\end{tabular}

TABLE 2 | Feature detection.

\begin{tabular}{|c|c|c|c|c|c|c|c|}
\hline Age & & Before & After & $\begin{array}{c}\% \text { Change } \\
\text { of the } \\
\text { mean }\end{array}$ & $t$ & $p$-Value & $N$ \\
\hline $\begin{array}{l}\text { Elementary } \\
\text { school }\end{array}$ & $\begin{array}{l}\text { Mean } \\
\text { SD }\end{array}$ & $\begin{array}{l}30.50 \\
20.78\end{array}$ & $\begin{array}{l}45.00 \\
30.23\end{array}$ & 32.22 & 5.7029 & 0.0001 & 75 \\
\hline $\begin{array}{l}\text { Middle } \\
\text { school }\end{array}$ & $\begin{array}{l}\text { Mean } \\
\text { SD }\end{array}$ & $\begin{array}{l}55.63 \\
31.77\end{array}$ & $\begin{array}{l}75.63 \\
36.16\end{array}$ & 26.45 & 2.3952 & 0.0195 & 75 \\
\hline High school & $\begin{array}{l}\text { Mean } \\
\text { SD }\end{array}$ & $\begin{array}{l}51.21 \\
27.66\end{array}$ & $\begin{array}{l}68.10 \\
34.31\end{array}$ & 24.81 & 3.4877 & 0.0004 & 70 \\
\hline College & $\begin{array}{l}\text { Mean } \\
\text { SD }\end{array}$ & $\begin{array}{l}71.59 \\
33.08\end{array}$ & $\begin{array}{r}108.15 \\
42.19\end{array}$ & 33.80 & 5.0585 & 0.0001 & 58 \\
\hline
\end{tabular}

TABLE 3 | Spearman's rho correlation coefficient.

\begin{tabular}{llll}
\hline NS & Correlation Coefficient & $\mathbf{0 . 0 7 0}$ & Elementary school \\
\hline NS & Correlation coefficient & 0.028 & Middle school \\
NS & Correlation coefficient & 0.154 & High School \\
NS & Correlation coefficient & 0.206 & College
\end{tabular}

performance was based on the Bloom's Taxonomy hierarchy that is represented in Figure 1.

\section{Participants}

Seventy high-school students all in grade 9 ( $M=17$ years), consisting of 38 females and 37 males, participated in the study. Each participant served as his/her own control. A mathematical test based on the Bloom Taxonomy was employed (19). Students were examined prior to and after a 10 -min period of walking. The following week each participant, at the same time, repeated a comparable task after a 10-min walk, and performance was re-examined. This then eliminated a temporal bias in the results and the groups were counterbalanced. The high-school level participants were divided into two groups, one consisting of low achievers, defined as those participants with a grade average of less than $60 \%$, and a second group consisting of high achievers, whose grade point average was greater than $60 \%$.

\section{Results}

The academically lower group obtained a significant increase of $6.29 \%$ in remember and $11.1 \%$ in understanding on the PISA tasks that evaluated performance within the Bloom's Taxonomy. Applying demonstrated an $8.4 \%$ increase and $19.6 \%$ in analyze 


\section{Bloom's Taxonomy}

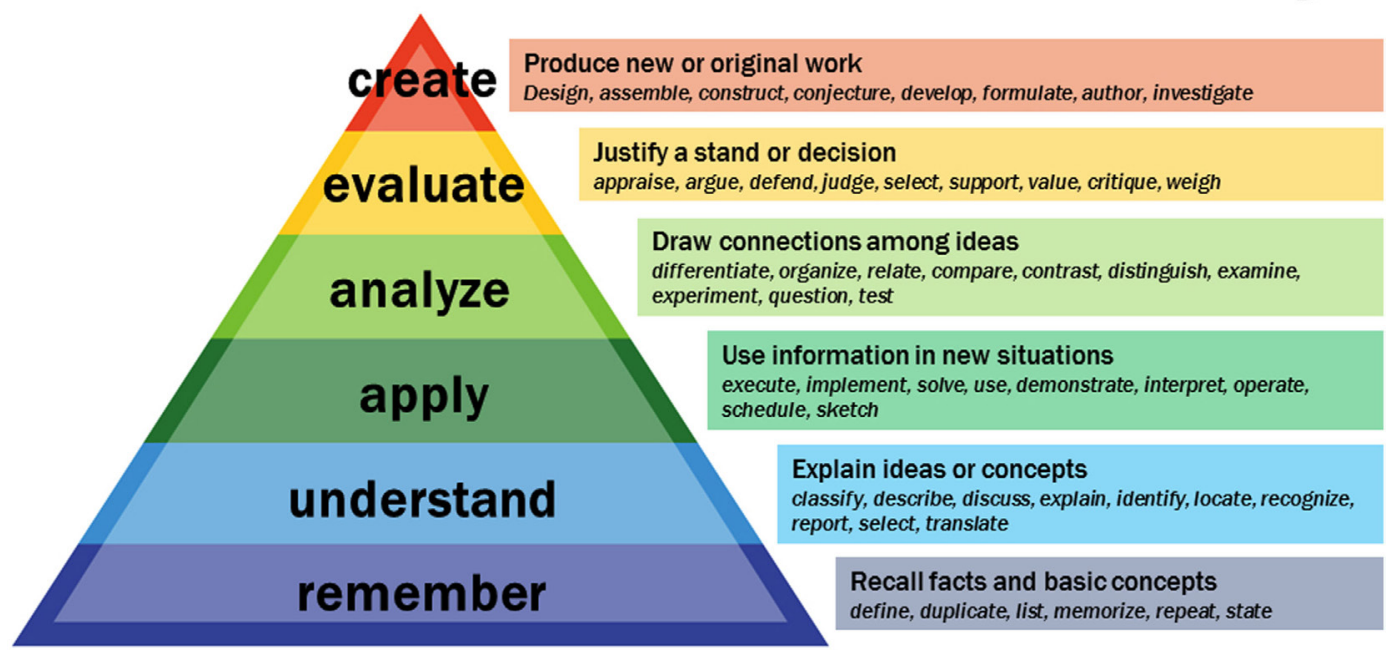

FIGURE 1 | Representation of Bloom's Taxonomy in the cognitive domain. The taxonomy provides a hierarchical model in order to categorize learning objectives in levels of specificity and complexity. Represented here is the knowledge-based cognitive domain that includes: remember (characterized by knowledge of specifics -terminology, specific facts, and ways); understanding (employing means of dealing with specifics them and knowledge of the universals and abstractions in a field such as understanding of facts and ideas by organizing, comparing, translating, interpreting, giving descriptions, and stating the main ideas); applying (involving acquired knowledge-e.g., problem solving in new situations); analyzing or breaking knowledge down into component parts; evaluating which is creating informed judgments and validating ideas and create which is the ability to create new knowledge.

TABLE 4 | Students with low achievement in mathematics.

\begin{tabular}{|c|c|c|c|c|c|c|}
\hline & & Remember & Understanding & Apply & Analyze & Final grade \\
\hline & SD & 1.70 & 1.64 & 1.68 & 1.15 & 5.46 \\
\hline & SD & 1.98 & 1.87 & 1.77 & 1.61 & 6.07 \\
\hline$\%$ Change of the mean & & $6.29 \%$ & $11.11 \%$ & $8.46 \%$ & $19.63 \%$ & $10.61 \%$ \\
\hline$t$ & & 2.474 & 3.6632 & 3.2937 & 3.4963 & 5.0182 \\
\hline
\end{tabular}

TABLE 5 | Students with high achievement in mathematics.

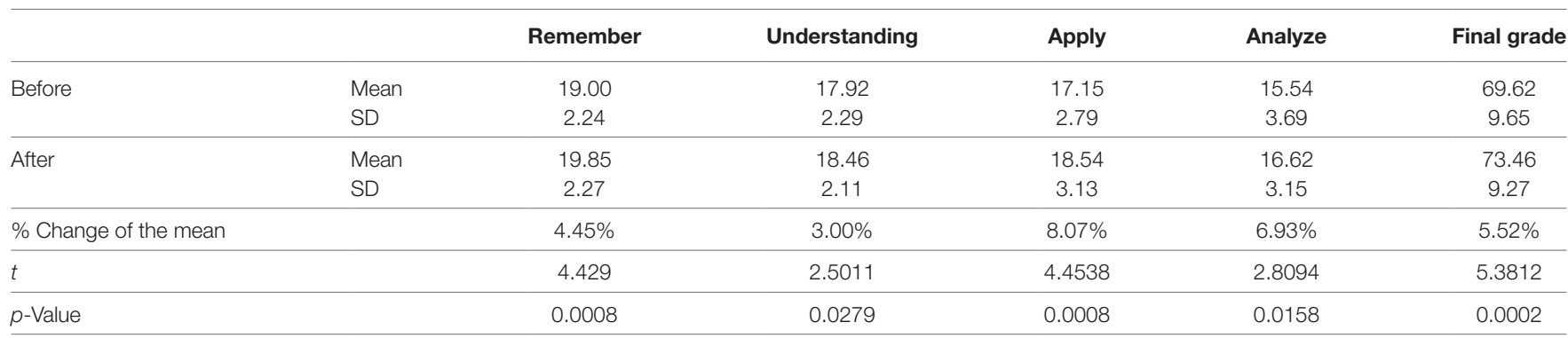

domains. The final grades for all participants increased by $10.6 \%$. The results for the low-achieving group are represented in Table 4.

The academically higher achieving group obtained a significant increase of $4.4 \%$ in remember and 3\% in understanding on PISA tasks that evaluated performance within the Bloom's Taxonomy. Applying demonstrated an $8.0 \%$ increase and $6.9 \%$ in analyze domains. The final grades for all participants increased by $5.5 \%$. The results for the low-achieving group are represented in Table 5.

\section{DISCUSSION}

Movement in the form of aerobic walking significantly enhances performance of children on tests of sequential memory requiring 
cognitive-motor interaction and on tests of feature detection associated with attentional focus. Older children demonstrated significantly greater improvement in sequencing tasks than did younger children and these children, in turn, performed significantly better on tasks requiring attentional focus. The results should generate both future research and impact on the nature of classroom instruction in the context of the relationship between movement and cognition.

Postural muscles, we have claimed elsewhere (21), were the chief channels for the evolution of motor and cognitive binding. For a more comprehensive review of the nature of evolutionary brain development, posture, brain size, and the implications for limitations of the pelvis as well as the genetic implications, the reader is referred to Melillo and Leisman (22) and Falk et al. (23).

Reduced postural activity in childhood harms natural exploration of the surrounding environment, thereby reducing the ability to learn from experiences. Deviations from normal postural development or from normal levels of postural activity can disrupt or delay cerebellar and cortical maturation and may disrupt the underlying oscillatory timing mec (24); hanisms on which motor and cognitive binding is based (25-29). As a result, cognition, more likely, evolved secondarily and in parallel to the evolution of human upright bipedalism. Although viewed as separate functions historically, it can be argued that complex motricity and cognition are functionally connected. The effect of this is that motricity is inextricably involved in cognitive skill acquisition $(21,24,30)$.

Motor and cognitive functions are both controlled by cerebellum, basal ganglia, and frontal lobe regions of the brain that cooperatively network to exercise control over the intentionality of movement and on executive functions that require the individual to anticipate and predict the requisite movements. Dysfunction associated with developmental delays all involve conditions of reduced optimization of brain integration that in turn disrupt executive function, frontal lobe-based behaviors, and articulation with motor components of the nervous system $(22,28,31)$.

Not uncommonly seen in children with developmental delays, is motor incoordination or "clumsiness," relating to posture and gait that supports the concept of "weak central coherence" that in turn relates to a processing bias for local and featural information and difficulty in extracting the essence of meaning, detecting missing or hidden figures or "seeing the big picture" in daily life experiences $(22,28,32)$.

Among the limitations of this study included the fact that missing was information about the ethnicity of the participants. Among the elementary school participants, the students were of

\section{REFERENCES}

1. Ratey JJ, Loehr JE. The positive impact of physical activity on cognition during adulthood: a review of underlying mechanisms, evidence and recommendations. Rev Neurosci (2011) 22:171-85. doi:10.1515/RNS.2011.017

2. Wang Y, Lobstein TIM. Worldwide trends in childhood overweight and obesity. Pediatr Obesity (2006) 1:11-25. doi:10.1080/17477160600586747

3. Kramer AF, Erickson KI. Capitalizing on cortical plasticity: influence of physical activity on cognition and brain function. Trends Cogn Sci (2007) 11:342-8. doi:10.1016/j.tics.2007.06.009 mixed ethnic background, but in the high-school population, all were Arabic speaking. Cultural effects are important issues to examine in future research. Additionally, mathematical skills as measured by PISA questions were only examined among highschool students and not among elementary school participants. In addition, a broad range of academic and cognitive skills were not examined in detail such as reading comprehension, reaction time, sensory-motor abilities, and the like. These are also the subjects of future research.

The tasks in this study simply examined the gross relation between walking as a form of motricity and feature detection and attention, cognitive, and academic performance. The results demonstrated the relationship and benefit between movement, in the form of walking, a postural function, and cognitive skills, such as critical feature detection.

\section{CONCLUSION}

The public health implications of the relationship between children's lifestyle and cognitive-motor interaction are significant. There exists a pandemic of physical inactivity among all age groups. We have predictions that sedentariness will continue to grow throughout the world in the near and long-term future (33). We can conclude that at least 10 min of walking has significant effect on mathematical problem-solving abilities in higher performing high school, but more so in lower performing students according to the results of testing mathematical problem-solving ability according to the Bloom's Taxonomy. Additionally, in all age groups $10 \mathrm{~min}$ of walking is a minimum that can affect performance in Simon-type memory and feature-detection tasks independent of children's age.

\section{ETHICS STATEMENT}

This study was carried out in accordance with the recommendations of the Research Committee of Oranim Academic College with written informed consent from all participant's parents or guardians. All subjects' parents or guardians gave written informed consent in accordance with the Declaration of Helsinki. The protocol was approved by the Research Committee of Oranim Academic College.

\section{AUTHOR CONTRIBUTIONS}

GL and RM wrote the paper. YZ, OM, SG, OM, SK-M, MA, and AK collected data and participated in the experimental design. $\mathrm{RM}, \mathrm{GL}$, and AO performed the statistical analyses.

4. Kramer AF, Erickson KI. Effects of physical activity on cognition, wellbeing, and brain: human interventions. Alzheimers Dement (2007) 3:S45-51. doi:10.1016/j.jalz.2007.01.008

5. McDonnell MN, Buckley JD, Opie GM, Ridding MC, Semmler JG. A single bout of aerobic exercise promotes motor cortical neuroplasticity. J Appl Physiol (2013) 114:1174-82. doi:10.1152/japplphysiol.01378.2012

6. Hillman CH, Buck SM, Themanson JR, Pontifex MB, Castelli DM. Aerobic fitness and cognitive development: event-related brain potential and task performance indices of executive control in preadolescent children. Dev Psychol (2009) 45:114-29. doi:10.1037/a0014437 
7. Smith AE, Goldsworthy MR, Garside T, Wood FM, Ridding MC. The influence of a single bout of aerobic exercise on short-interval intracortical excitability. Exp Brain Res (2014) 232:1875-82. doi:10.1007/s00221-0143879-z

8. Leisman G. Brain networks, plasticity, and functional connectivities inform current directions in functional neurology and rehabilitation. Funct Neurol Rehab Ergon (2011) 2:315-56.

9. Kamijo K, Khan NA, Pontifex MB, Scudder MR, Drollette ES, Raine LB, et al. The relation of adiposity to cognitive control and scholastic achievement in preadolescent children. Obesity (Silver Spring) (2012) 20:2406-11. doi:10.1038/oby.2012.112

10. Hillman CH, Erickson KI, Kramer AF. Be smart, exercise your heart: exercise effects on brain and cognition. Nat Rev Neurosci (2008) 9:58-65. doi:10.1038/ nrn2298

11. Cotman CW, Berchtold NC. Exercise: a behavioral intervention to enhance brain health and plasticity. Trends Neurosci (2002) 25:295-301. doi:10.1016/ S0166-2236(02)02143-4

12. Ben-Soussan TD, Piervincenzi C, Venditti S, Verdone L, Caserta M, Carducci F. Increased cerebellar volume and BDNF level following quadrato motor training. Synapse (2015) 69:1-6. doi:10.1002/syn.21787

13. Nishijima T, Llorens-Martín M, Tejeda GS, Inoue K, Yamamura Y, Soya H, et al. Cessation of voluntary wheel running increases anxiety-like behavior and impairs adult hippocampal neurogenesis in mice. Behav Brain Res (2013) 245:34-41. doi:10.1016/j.bbr.2013.02.009

14. Chaddock-Heyman L, Erickson KI, Holtrop JL, Voss MW, Pontifex MB, Raine LB, et al. Aerobic fitness is associated with greater white matter integrity in children. Front Hum Neurosci (2014) 8:584. doi:10.3389/fnhum. 2014.00584

15. Hollingshead AB, Redlich FC. Social Class and Mental Illness: Community Study. Hoboken, NJ: Wiley (1958).

16. Simon JR, Wolf JD. Choice reaction time as a function of angular stimulusresponse correspondence and age. Ergonomics (1963) 6:99-105. doi:10.1080/ 00140136308930679

17. Starr C, Taggart R, Evers C, Starr L. Biology: The Unity and Diversity of Life. 13th ed. Boston, MA: Brooks Cole (2013).

18. Bloom BS. Taxonomy of Educational Objectives. Vol. 1: Cognitive Domain. New York: McKay (1956). p. 20-4.

19. Stacey K. The International Assessment of Mathematical Literacy: PISA 2012 Framework and Items. In: Cho S, editor. Selected Regular Lectures from the 12th International Congress on Mathematical Education. New York, NY: Springer (2015).

20. OECD. PISA: Take the Test. (1999). Available from: https://www.oecd.org/pisa/ pisaproducts/Take\%20the\%20test\%20e\%20book.pdf (Accessed: December $17,2017)$.

21. Leisman G, Moustafa AA, Shafir T. Thinking, walking, talking: integratory motor and cognitive brain function. Front Public Health (2016) 4:94. doi:10.3389/fpubh.2016.00094

22. Melillo R, Leisman G. Neurobehavioral Disorders of Childhood: An Evolutionary Approach. New York, NY: Springer (2010).
23. Falk D, Zollikofer CP, Morimoto N, Ponce de León MS. Metopic suture of Taung (Australopithecus africanus) and its implications for hominin brain evolution. Proc Nat Acad Sci U S A (2012) 109:8467-70. doi:10.1073/ pnas.1119752109

24. Ericsson I. Effects of Increased Physical Education and Motor Skills Acquisition on Scholastic Performance. (2017). p. 1-20. Available from: http://idrottsforum.org/ wp-content/uploads/2017/09/ericsson170907.pdf (Accessed: April 1, 2018).

25. Vercruyssen M, Simonton K. Effects of posture on mental performance: we think faster on our feet than on our seat. In: Lueder R, Noro K, editors. Hard Facts about Soft Machines: The Ergonomics of Seating. Bristol, PA: Taylor \& Francis (1994). p. 119-32.

26. Alperin N, Lee SH, Sivaramakrishnan A, Hushek SG. Quantifying the effect of posture on intracranial physiology in humans by MRI flow studies. J Magn Reson Imaging (2005) 22:591-6. doi:10.1002/jmri.20427

27. Dijkstra K, Kaschak MP, Zwaan RA. Body posture facilitates retrieval of autobiographical memories. Cognition (2007) 102:139-49. doi:10.1016/j. cognition.2005.12.009

28. Leisman G, Braun-Benjamin O, Melillo R. Cognitive-motor interactions of the basal ganglia in development. Front Syst Neurosci (2014) 8:16. doi:10.3389/ fnsys.2014.00016

29. Leisman G, Rojas RR, Batista K, Carballo M, Morales JM, Iturria Y, et al. Measurement of axonal fiber connectivity in consciousness evaluation. IEEE 28th Convention of Electrical and Electronics Engineers in Israel. (2014). IEEE Cat. No: CFP14417-CDR.

30. Voelcker-Rehage C, Niemann C, Hübner L, Godde B, Winneke AH. Benefits of physical activity and fitness for lifelong cognitive and motor developmentbrain and behavior. Sport Exer Psychol Res (2016) 18:43-73. doi:10.1016/ B978-0-12-803634-1.00003-0

31. Leisman G, Melillo R. The basal ganglia: motor and cognitive relationships in a clinical neurobehavioral context. Rev Neurosci (2013) 24:9-25. doi:10.1515/ revneuro-2012-0067

32. Happé F, Frith U. The weak coherence account: detail-focused cognitive style in autism spectrum disorders. JAutism Dev Disord (2006) 36:5-25. doi:10.1007/s10803-005-0039-0

33. Ng SW, Popkin BM. Time use and physical activity: a shift away from movement across the globe. Obes Rev (2012) 13:659-80. doi:10.1111/j.1467789X.2011.00982.x

Conflict of Interest Statement: The authors declare that the research was conducted in the absence of any commercial or financial relationships that could be construed as a potential conflict of interest.

Copyright () 2018 Mualem, Leisman, Zbedat, Ganem, Mualem, Amaria, Kozle, Khayat-Moughrabi and Ornai. This is an open-access article distributed under the terms of the Creative Commons Attribution License (CC BY). The use, distribution or reproduction in other forums is permitted, provided the original author $(s)$ and the copyright owner are credited and that the original publication in this journal is cited, in accordance with accepted academic practice. No use, distribution or reproduction is permitted which does not comply with these terms. 